\title{
UTILIZAÇÃO DO LASER DE BAIXA POTÊNCIA: IMPORTÂNCIA DA DESCRIÇÃO DOS PARÂMETROS DE IRRADIAÇÃO
}

\author{
Utilization of low level laser: \\ importancy of irradiantion parameters description
}

Mariana Marquezan ${ }^{1}$, Thiago Chon Leon Lau², Bruno Lopes da Silveira ${ }^{3}$ e Mônica Tirre de Souza Araújo ${ }^{4}$

\begin{abstract}
RESUMO
O efeito bioestimulador do laser de baixa potência tem sido amplamente estudado nas últimas décadas. Cerca de 300 trabalhos foram publicados no último ano, porém variações metodológicas e a omissão de dados importantes é um problema que dificulta a comparação entre os estudos e a reprodução de experimentos. Através de uma discussão crítica, os autores sugerem uma detalhada descrição de protocolo de irradiação.
\end{abstract}

Palavras-chave: lasers; terapia a laser de baixa potência

\section{SUMMARY}

The biostimulatory effect of low level laser therapy has been widely studied in recent decades. About 300 papers were published last year, but methodological differences and the omission of important data is an issue that makes it difficult to compare studies and replicate experiments. Here the authors performed a critical review of the literature and suggested a detailed description of irradiation protocols.

Keywords: lasers; low-level laser therapy

\section{INTRODUÇÃO}

As primeiras publicações sobre laser na área da saúde datam da década de 60, quando médicos europeus estudaram o efeito bioestimulador do laser. Desde então, diversas pesquisas têm sido realizadas sobre esse tema nas áreas da Medicina, Medicina Veterinária, Fisioterapia e Odontologia, tendo um saldo de mais de cinco mil trabalhos com relação à laserterapia, sendo mais de trezentos deles publicados no último ano.

Apesar da grande quantidade de estudos produzidos, ainda não se sabe exatamente o mecanismo de ação do laser nos tecidos ${ }^{1,2,3}$ e pesquisadores da área podem encontrar dificuldade na comparação e reprodução de estudos devido a variações metodológicas nas publicações ${ }^{4}$, além da omissão de certos dados e/ou diferença na descrição dos parâmetros referentes ao laser ${ }^{5}$. Para caracterização da aplicação de laser, os parâmetros utilizados precisam ser descritos em detalhes ${ }^{6}$. Estudos com laser terapêutico deveriam fornecer em pormenores o protocolo de irradiação, onde deveria constar a descrição do aparelho utilizado, a fluência ou a irradiância a fim de caracterizar a dose, a energia total fornecida, o modo de irradiação, o tempo de aplicação, além da descrição minuciosa do número e localização dos pontos de aplicação e do intervalo entre irradiações.

O objetivo desse trabalho é descrever parâmetros importantes a serem citados na caracterização do protocolo

Trabalho realizado no Departamento de Odontopediatria e Ortodontia da Universidade Federal do Rio de Janeiro (UFRJ), sendo parte da Dissertação de Mestrado.

${ }_{1}^{1}$ Mestre em Odontologia - Ortodontia da Universidade Federal do Rio de Janeiro (UFRJ).

${ }^{2}$ Aluno do Programa de Mestrado em Odontologia - Ortodontia da UFRJ.

${ }^{3}$ Doutor em Odontologia - Dentística Restauradora da Universidade de São Paulo (USP), Professor do Curso de Odontologia da UNIFRA, do Curso de Aperfeiçoamento em Laser da International Institute of Medical and Dental Science (IIMDS) Portugal e Professor Colaborador do NuPEN.

${ }^{4}$ Mestre e Doutora em Odontologia - Ortodontia (UFRJ), Professora Adjunto do Departamento de Odontopediatria e Ortodontia da UFRJ. 
de aplicação do laser de baixa potência em pesquisas científicas.

\section{DESCRIÇÃO DOS PROTOCOLOS}

A descrição do protocolo de irradiação se inicia pela descrição do aparelho a ser utilizado. Não é necessário fornecer a marca/ modelo comercial, mas dados como comprimento de onda, potência e área da ponteira de entrega (spot) devem ser especificados.

O comprimento de onda (ë) é um parâmetro equivalente à distância entre dois picos consecutivos de uma onda luminosa e é medido em nanômetros (nm). As terapias com laser de baixa potência compreendem a faixa entre 500 e $1100 \mathrm{~nm}^{7}$. Diferentes comprimentos de onda apresentam diferentes coeficientes de absorção para um mesmo tecido alvo ${ }^{8,9}$ e cada equipamento de laser opera com um comprimento de onda dependente de seu meio ativo. Dessa maneira, o operador deve conhecer o comprimento de onda indicado para o tecido em que vai trabalhar, pois é ele que define a profundidade de penetração do laser no tecido alvo. Para obter-se bioestimulação em tecidos profundos, como tecido ósseo, tem-se utilizado lâseres infravermelhos, com destaque para o laser de arseaneto de gálio e alumínio (Ga-Al-As), com comprimentos de onda entre 780 e $960 \mathrm{~nm}$. A não afinidade por hemoglobina e água faz com que esse laser penetre nos tecidos mais profundos ${ }^{10,11}$. Já para reparo de feridas, tem-se utilizado comprimentos de onda menores, na faixa do vermelho, compreendido entre as faixas de $626-780 \mathrm{~nm}^{7,12,13,14,15}$.

A potência (Pot) do aparelho corresponde à intensidade da luz laser e é medida em Watts (W). É uma característica que divide os lâseres em dois grandes grupos: os de alta potência, também ditos cirúrgicos, onde a potência de emissão encontra-se acima de $500 \mathrm{~mW}$, e os de baixa potência, ditos não cirúrgicos ou terapêuticos. A potência é importante para o cálculo da fluência, irradiância e energia total.

A área a ser irradiada (S), na técnica pontual, equivale à área do spot ou da ponteira do equipamento (Figuras 1). Essa é também importante para o cálculo da fluência e sua unidade é $\mathrm{cm}^{2}$. Tem-se a opção de fornecer o diâmetro ou raio da ponteira de aplicação em vez da área, pois essa pode ser facilmente calculada através da fórmula da área da circunferência $\left(S=ð . r^{2}\right)$, visto que as ponteiras de aplicação são circulares (Figuras 2).
Figura 1- Área irradiada, na técnica pontual, equivalente à área da ponteira, pois há contato direto.

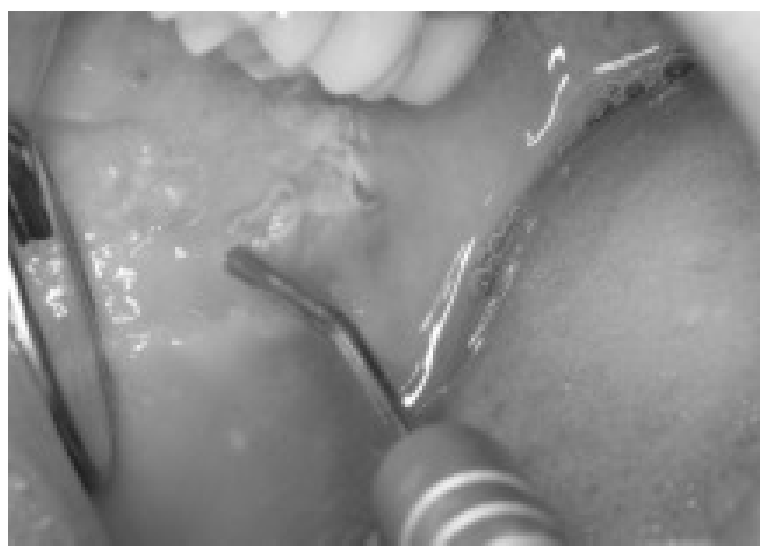

Figura 2- Ponteira de aplicação do laser de baixa potência.

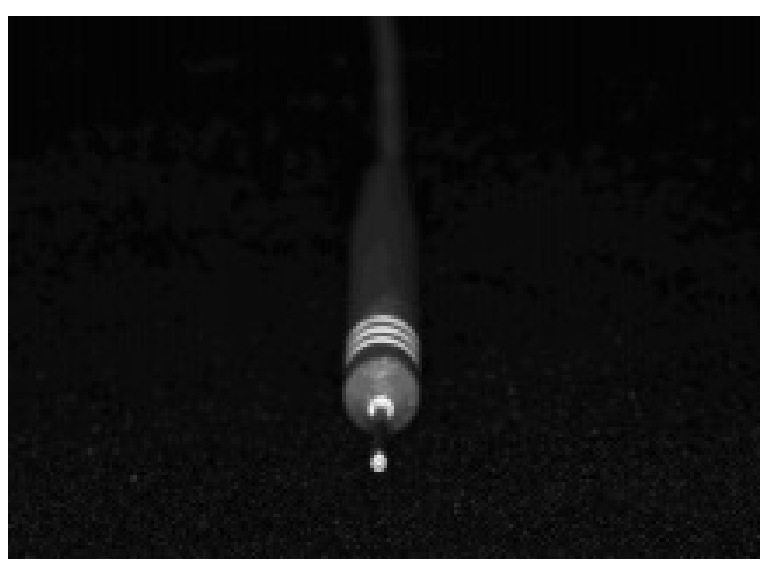

FLUENNCIA

Também chamada Densidade de Energia (DE) ou Dosimetria, é a quantidade de energia depositada no tecido num dado tempo (num determinado ponto em uma sessão). É calculada multiplicando-se a potência do aparelho (Pot), pelo tempo de exposição do tecido à luz (t), em segundos, e dividindo-se esse resultado pela área irradiada (S), que corresponde à área da ponteira de aplicação na técnica de aplicação pontual (Quadro 1). A unidade utilizada é J/cm².É imprescindível citar a fluência utilizada num experimento ou procedimento clínico a ser publicado, pois se sabe que a irradiação laser pode modificar os processos celulares de 


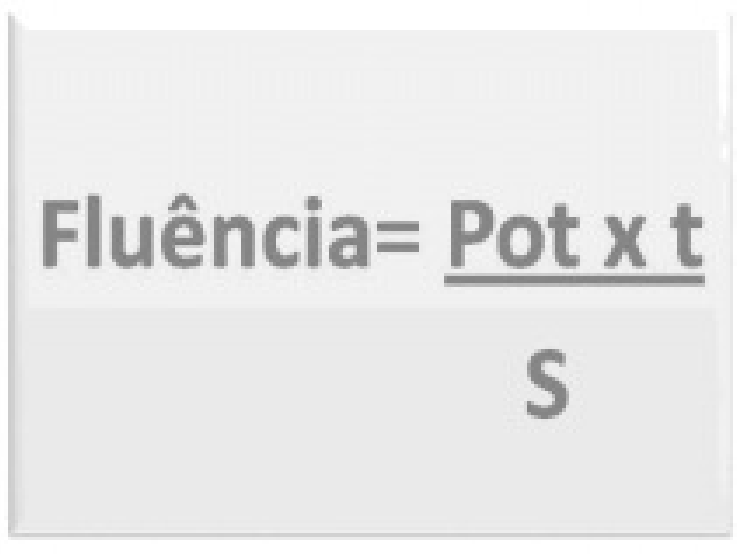

Quadro 1- Fórmula da Fluência ou Densidade de Energia

maneira dependente da fluência $\left(\mathrm{J} / \mathrm{cm}^{2}\right)$ ou dose ${ }^{7,16}$, existindo uma zona estreita e bem definida de parâmetros da luz capaz de gerar efeito estimulador ${ }^{17}$.

Alternativamente ao fornecimento da fluência, pode-se informar a irradiância ou densidade de potência (DP) que é a

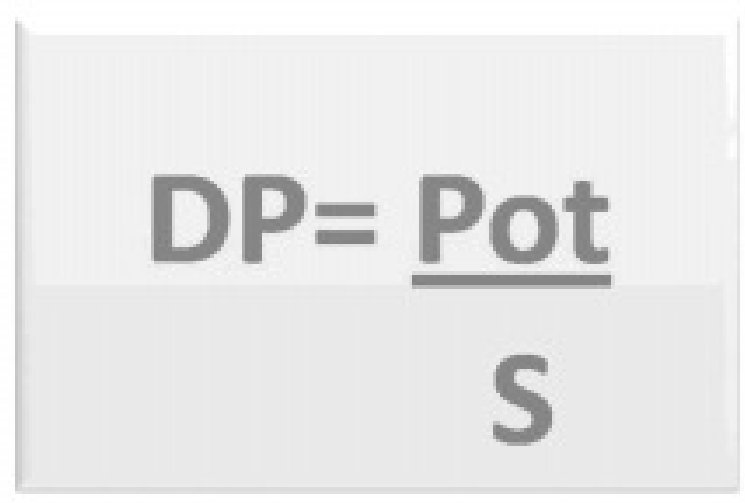

Quadro 2- Fórmula da Densidade de Potência ou Irradiância

potência multiplicada pelo tempo de aplicação do laser expressa em W/cm ${ }^{2}$ (Quadro 2). Informando-se também o tempo de aplicação em cada ponto, pode-se calcular a fluência.

Segundo Fukuda; Malfatti ${ }^{6}$ o parâmetro mais utilizado, na literatura, para definir a "dose" é a densidade de energia, entretanto, ela por si só não é capaz de definir a dose, sendo necessário mencionar também a energia total ou final.

\section{ENERGIA TOTAL OU FINAL}

Em laserterapia, energia representa a quantidade de luz laser que está sendo depositada no tecido. É definida multiplicando-se a potência (W) pelo tempo total de exposição (s) ao final de cada sessão de irradiação. O resultado obtido é representado em Joule
(J). É importante citá-la junto à densidade de energia para que se caracterize a dose utilizada ${ }^{6}$. Entretanto, a citação da energia final apenas, sem referenciar a fluência, não fornece os subsídios necessários para a reprodução do estudo ou para utilização clínica dos protocolos de aplicação de laser com aparelhos de outras marcas comerciais, pois a secção das ponteiras dos aparelhos não é padronizada.

\section{TEMPO}

Apesar de ser extremamente importante a descrição do tempo utilizado em cada ponto de aplicação, esse parâmetro isolado não é capaz de expressar a dose utilizada mesmo que se tratem de irradiações com aparelhos que apresentem mesma potência e comprimento de onda, visto que as secções de ponteira são diferentes, mudando assim a fluência. Para o cálculo da fluência, o tempo deve ser expresso em segundos (s).

\section{PONTOS DE APLICAÇÃO}

Em grande parte das pesquisas com laser, têm-se utilizado a técnica de aplicação pontual em detrimento da aplicação por varredura da área ${ }^{11,18,19,20,21}$. Essa técnica permite o exato cálculo da fluência, pois a área da ponteira de aplicação é equivalente à área irradiada. Deve-se ressaltar a importância da descrição do número e local dos pontos de aplicação, inclusive ilustrando-os com fotografias ou figuras esquemáticas se possível.

\section{INTERVALO DE APLICAÇÃO}

Alguns protocolos de aplicação do laser contemplam única aplicação ${ }^{12,13,22}$, enquanto em outros há múltiplas sessões $^{18,19,20,21,11}$. Nesses, devem-se descrever os intervalos de aplicação, seja em horas ou em dias. Por exemplo, o protocolo para aplicação do LBP em ulcerações aftosas recorrentes é composto de aplicações diárias até que haja cicatrização ou enquanto houver desconforto, já para reparação óssea em período pós-cirúrgico, indicam-se irradiações a cada 48 horas por $14 \operatorname{dias}^{23}$.

\section{MODO DE IRRADIAÇÃO}

Os lâseres podem emitir energia de maneira contínua ou pulsada. No modo pulsado, a freqüência dos pulsos é medida em hertz (Hz). Esse dado é de importe descrição, pois se tem verificado que alterações na frequência de irradiação podem influenciar no resultado do tratamento ${ }^{24}$. Tem-se preferido o modo contínuo por facilitar o cálculo da dose. 


\section{EXEMPLO DA DESCRIÇÃO DE PARÂMETROS DE IRRADIAÇÃO}

A fim de sintetizar o tema abordado em um exemplo, será descrito um protocolo de irradiação de LBP para aceleração da movimentação ortodôntica. KAWASAKI; SHIMIZU ${ }^{19}$ sugeriram o uso do laser de Ga-Al-As, com comprimento de onda de 830 $\mathrm{nm}$, fluência (DE) de $6000 \mathrm{~J} / \mathrm{cm}^{2}$ e energia total de $54 \mathrm{~J}$ distribuída em 3 pontos de aplicação. Tendo-se, por exemplo, um aparelho com potência de $100 \mathrm{~mW}(0,1 \mathrm{~W})$ e área da ponteira de 0,003 $\mathrm{cm}^{2}$, conclui-se que o tempo de irradiação deve ser de $180 \mathrm{~s} \mathrm{em}$ cada ponto $(\mathrm{DE}=\mathrm{Pot} \mathrm{x} / \mathrm{S})$. Para confirmar esse tempo, pode-se fazer outro cálculo, o da energia total. Sendo a energia total a multiplicação da potência pelo tempo total de irradiação numa sessão, verifica-se que o tempo total de irradiação é de $540 \mathrm{~s}$. Sabendo que existem três pontos de aplicação, a cada um deles deverão ser aplicados $180 \mathrm{~s}$.

\section{CONCLUSÕES}

A descrição dos protocolos de irradiação por laser de baixa potência deve ser extremamente detalhada a fim de permitir a reprodução do estudo ou mesmo elucidar o protocolo ao clínico que pretende utilizar a laserterapia em consultório, visto que pequena variação em um parâmetro apenas, como fluência ou comprimento de onda, pode determinar efeito estimulador ou inibidor do laser.

\section{REFERENCIAS BIBLIOGRÁFICAS}

1. Ozawa Y, Shimizu N, Kariya G, Abiko, Y. Low-Energy Laser Irradiation Stimulates Bone Module Formation At Early Stages Of Cell Culture In Rat Calvarial Cells. Bone. 1998; 22(4):347-354.

2. Coombe AR, Ho CT, Darendeliler MA. Hunter N, Philips Jr, Chapple CC, Yum LW. The effects of low level laser irradiation on osteoblastic cells. Clin Orthod Res. 2001; 4(1):3-14.

3. Rocha JCT. Terapia laser, cicatrização tecidual e angiogênese. Revista Brasileira em Promoção da Saúde. 2004; 17(1):44-48.

4. Walsh LJ. The current status of low level laser therapy in dentistry. Part 1. Soft tissue applications. Aust Dent J. 1997; 42(4):247-54.

5. Posten W, Wrone DA, Dover JS, Arndt KA, Silapunt S, Alam M. Low-level laser therapy for wound healing: mechanism and efficacy. Dermatol Surg. 2005; 31(3):334-40.

6. Fukuda Ty; Malfatti Ca. Analysis Of Low-Level Laser Therapy Doses In Brazilian Equipament. Rev Bras Fisioter. 2008; 12(1):704.

7. Houreld Nn; Abrahamse H. Laser Light Influences Cellular Viability And Proliferation In Diabetic-Wounded Fibroblast Cells In A DoseAnd Wavelength-Dependent Manner. Lasers Med Sci. 2008; 23:11-
18.

8. Almeida-lopes L. Análise in vitro da Proliferação Celular de Fibroblastos da Gengiva Humana Tratados com Laser de Baixa Potência. [Dissertação de Mestrado]. São José dos Campos: Instituto de Pesquisa e Desenvolvimento, Universidade do Vale do Paraíba,1999.

9. Pinheiro, Alb. Interação Tecidual. In: Brugnera Jr, A; Pinheiro, Alb. Lasers Na Odontologia Moderna. São Paulo: Pancast, 1998. Cap3: 47-62.

10. Saito S, Shimizu N. Stimulatory effect of low-power laser irradiation on bone regeneration in midpalatal suture during expansion in the rat. Am J Orthod Dentofac Orthop.1997; 111:525-32.

11. Youssef M, Ashkar S, Hamade E, Gutknecht N, Lampert F, Mir M. The effect ol low-level aser therapy during orthodontic movement: a prelinary study. Lasers Med Sci. 2007; 23:27-33. 12. Fung Dt, Ng Gy, Leung Mc, Tay Dk. Effects Of A Therapeutic Laser On The Ultrastructural Morphology Of Repairing Medial Collateral Ligament In A Rat Model. Lasers Surg Med. 2003; 32 (4):286-93.

13. Medrado Ar, Pugliese Ls, Reis Sr, Andrade Za. Influence Of Low Level Laser Therapy On Wound Healing And Its Biological Action Upon Myofibroblasts. Lasers Surg Med. 2003; 32(3):23944.

14. Pugliese LS, Medrado AP, Reis SR, Andrade Z. The influence of low-level laser therapy on biomodulation of collagen and elastic fibers. Pesqui Odontol Bras. 2003; 17(4):307-13.

15. Schlager A, Oehler K, Huebner K, Schmuth M, Spoetl L. Healing of burns after treatment with 670-nanometer low-power laser light. Plast Reconstr Surg. 2000; 105(5):1635-9.

16. Hawkins Dh; Abrahamse H. The Role Of Laser Fluence In Cell Viability, Proliferation, And Membrane Integrity Of Wounded Human Skin Fibroblasts Following Helium-Neon Laser Irradiation. Lasers Surg Med. 2006; 38(1):74-83.

17. Karu, Ti. Low-Power Laser Therapy. In: Vo-Dinh, T. Biomedical Photonics Handbook. Boca Raton: Crc Press, 2003. Cap. 48: 1-25.

18. Cruz D R, Kohara E K, Ribeiro M S, Wetter N U. Effects Of Low-Intensity Laser Therapy On The Orthodontic Movement Velocity Of Human Teeth: A Preliminary Study. Lasers Surg Med. 2004; 35(2):117-20.

19. Kawasaki K; Shimizu N. Effects Of Low-Energy Laser Irradiation On Bone Remodeling During Experimental Tooth Movement In Rats. Lasers Surg Med. 2000; 26(3):282-91.

20. Limpanichkul W, Godfrey K, Srisuk N, Rattanayatikul C. Effects Of Low-Level Laser Therapy On The Rate Of Orthodontic Tooth Movement. Orthod Craniofac Res. 2006; 9(1):38-43.

21. Seifi M, Shafeei H A, Daneshdoost S, Mir M. Effects of two types of low-level laser wave lengths (850 and $630 \mathrm{~nm}$ ) on the orthodontic tooth movements in rabbits. Lasers Med Sci. 
22(4):261-4.

22. Pessoa Es, Melhado Rm, Theodoro Lh, Garcia Vg. A Histologic Assessment Of The Influence Of Low-Intensity Laser Therapy On Wound Healing In Steroid-Treated Animals. Photomed Laser Surg. 2004; 22(3):199-204.
23. Almeida-Lopes L. Laserterapia na Odontologia. OdontoClínica Odontológica Integrada, Bauru, v. 1, p. 1-89, 2004.

24. Ueda Y, Shimizu N. Effects of pulse frequency of low-level laser therapy (LLLT) on bone nodule formation in rat calvarial cells. J Clin Laser Med Surg. 2003;21(5):271-7.

Endereço para correspondência:

Avenida Brigadeiro Trompowsky, sem número, Ilha do Fundão

Rio de Janeiro, RJ, CEP 21941-590

Telefone (21) 25902727

Email: monicatirre@uol.com.br , 